\title{
Diagnosis and management of acute coronary syndromes
}

\section{Joanne Eng-Frost (D) \\ Cardiology advanced trainee' \\ Derek Chew \\ Matthew Flinders fellow and \\ Professor in Cardiology' \\ ${ }^{1}$ Flinders Medical Centre, Southern Adelaide Local Health Network}

\section{Keywords}

acute coronary syndromes, antiplatelet drugs, antithrombotic therapy, myocardial infarction, troponin, unstable angina

Aust Prescr 2021;44:180-4 https://doi.org/10.18773/ austprescr.2021.049

\section{SUMMARY}

Acute coronary syndromes are a significant cause of morbidity and mortality in Australia. Outcomes are likely to be improved by rapid and accurate diagnosis, and early intervention.

The development of high-sensitivity troponin assays has revealed previously unrecognised types of myocardial injury, for which conventional management guidelines for myocardial infarction may not confer similar benefits. The distinction between myocardial injury and myocardial infarction has therefore become increasingly important.

Once the diagnosis of acute myocardial infarction has been made, individualised acute reperfusion strategies including percutaneous coronary intervention or fibrinolytic therapy should be considered. Secondary prevention strategies should be implemented before hospital discharge.

\section{Introduction}

Acute coronary syndromes encompass myocardial infarction and unstable angina. Although survival has improved, acute coronary syndrome remains a significant cause of morbidity and mortality in Australia. Previous management guidelines largely focused on timely coronary reperfusion to reduce the size of the infarcted area. Current management guidelines focus on the need to establish an accurate diagnosis of acute coronary syndrome. High-sensitivity troponin assays have led to greater and earlier identification of patients experiencing an acute coronary syndrome. However, the lowered troponin reference threshold has also unmasked a host of previously unrecognised types of myocardial injury for which conventional management may not confer similar survival benefits.

\section{Differentiating myocardial infarction from myocardial injury}

A diagnosis of myocardial infarction can no longer be based solely on elevated concentrations of troponin. Myocardial infarction as a result of atherosclerotic plaque rupture is termed a type 1 myocardial infarction in the Fourth Universal Definition of Myocardial Infarction (see Fig.).' The diagnosis requires elevated troponins in conjunction with a clinical history consistent with myocardial ischaemia, ischaemic changes on the ECG, or ancillary evidence of coronary ischaemia on cardiac imaging if available.

Myocardial injury is defined as a troponin value at or above the 99th percentile upper reference limit derived from a normal reference population. ' This may be acute or chronic.
It is important to differentiate that an acute myocardial injury may also be termed a type 2 myocardial infarction. In type 2 myocardial infarction, acute atherosclerotic plaque rupture is not a feature. 'The acute myocardial injury arises due to a mismatch between oxygen supply and demand, when there is an acute stressor such as intercurrent illness, acute anaemia or sustained tachyarrhythmia, in patients with known or presumed coronary artery disease. The extent of the injury depends on pre-existing coronary artery disease, non-cardiac comorbidities and the severity of the acute stress.

A chronic elevation of troponin concentrations is more commonly seen in older patients with multiple comorbidities who have non-coronary conditions that result in chronically increased myocardial demands. Examples are chronic renal impairment and chronic heart failure.

\section{Acute management}

All acute care facilities with the capacity to treat myocardial infarction should have systematic processes and infrastructure to expedite urgent consultation with a cardiologist, including telephone consultation.

It is crucial to determine if there is ST-elevation on the ECG and to identify acute arrhythmic and haemodynamic complications. Acute management of such complications should be guided by the Australian Resuscitation Council Guidelines for Advanced Life Support, ${ }^{2}$ in addition to support from intensive care or emergency medical retrieval services.

\section{Initial management}

Aspirin and other drugs are used in the early management of acute coronary syndrome. 


\section{Fig. Fourth universal definition of myocardial infarction}

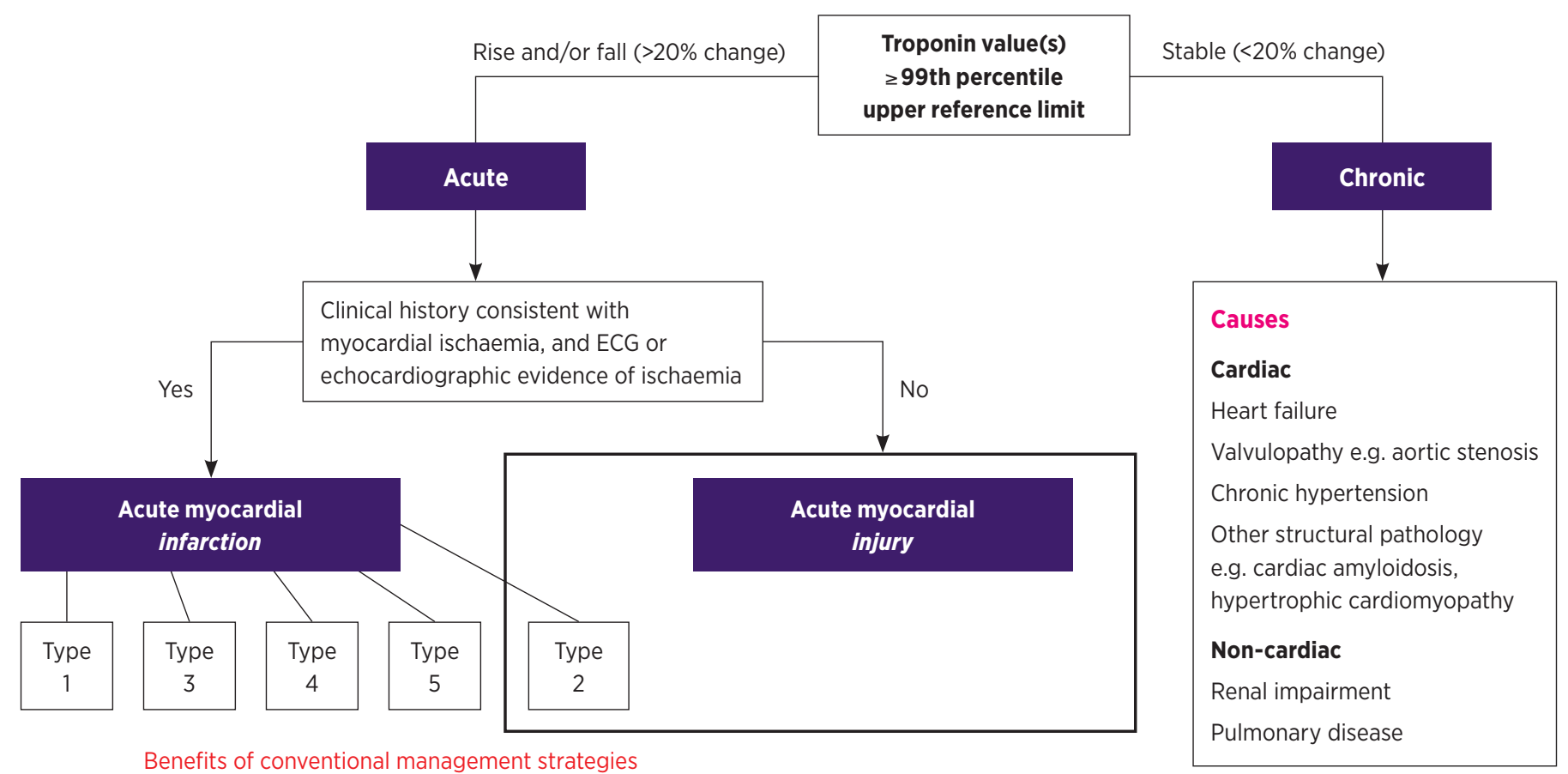

in non-type 1 myocardial infarctions have not yet been demonstrated.

\section{Types of acute myocardial infarction}

\section{Type 1 = plaque rupture}

Spontaneous myocardial infarction secondary to atherosclerotic plaque rupture

\section{Type $\mathbf{2}$ = ischaemic imbalance}

Tachyarrhythmia, anaemia, respiratory failure, hypotension/shock, severe hypertension, coronary vasospasm, acute myocarditis

\section{Type $\mathbf{3}$ = biomarker values unavailable}

Cardiac death with symptoms suggestive of myocardial ischaemia and presumed new ischaemic ECG changes/left bundle branch block, however death occurred before initial or serial blood samples could be obtained

\section{Type $\mathbf{4}$ = percutaneous coronary intervention-related}

$4 a$ - secondary to procedure e.g. coronary dissection, no re-flow, distal embolisation

$4 \mathrm{~b}$ - associated with stent or scaffold thrombosis

$4 \mathrm{c}$ - in-stent restenosis following balloon angioplasty in infarct territory when no other culprit lesion can be identified

Type $\mathbf{5}=$ coronary artery bypass grafting-related

Direct traumatic injury to myocardium

\section{Nitrates}

Glyceryl trinitrate is a potent vasodilator used to increase coronary blood flow. It is given sublingually or via intravenous infusion to provide symptom relief. Due to the potential adverse effect of hypotension, it should not be used if patients are hypotensive, or taking a phosphodiesterase- 5 inhibitor.

\section{Opioids}

Morphine and fentanyl are potent analgesics. They are recommended for the relief of ischaemic chest pain.

\section{Oxygen}

The routine use of oxygen supplementation is not recommended in patients who are not hypoxic.

\section{ST-elevation myocardial infarction}

Patients with an ST-elevation myocardial infarction (STEMI) require interventions to re-establish coronary blood flow and minimise morbidity and mortality. This can be achieved by percutaneous coronary intervention or fibrinolytic therapy. Patient choice, ischaemic and bleeding risks must be carefully considered, ${ }^{3}$ especially in patients with significant comorbidity or a short life expectancy.

In the absence of life-limiting comorbidities and contraindications, patients presenting within 12 hours of the onset of chest pain require emergency reperfusion. Primary percutaneous intervention is preferred if it can feasibly be performed within 
90 minutes of first medical contact. ${ }^{4}$ For Australians unable to reach a capable facility within this time, fibrinolytic therapy remains a life-saving option and should be administered promptly. ${ }^{5}$ Early transfer for primary percutaneous intervention within 24 hours is reasonable, ${ }^{6}$ however immediate transfer for rescue primary percutaneous intervention is critical if fibrinolytic therapy fails. This is evidenced by a reduction of $50 \%$ or less in ST-elevation on an ECG 60-90 minutes post-fibrinolysis, haemodynamic instability or persistent chest pain.?

\section{Non-ST-elevation myocardial infarction}

Compared to STEMI, the diagnosis of a non-STEMI is more complex to establish, due to the rising incidence of non-type 1 myocardial infarctions and myocardial injuries. Interpretation of the complete clinical presentation in the context of the Fourth Universal Definition of Myocardial Infarction is recommended rather than relying on troponin elevation alone. After a diagnosis of non-STEMI has been confirmed, acute management includes antiplatelet therapy and anticoagulation, and coronary investigation should be considered. This is because rates of recurrent myocardial infarction, refractory angina and rehospitalisation for recurrent acute coronary syndrome can be significantly decreased with percutaneous revascularisation. ${ }^{8-12}$ In the absence of life-limiting comorbidities and contraindications, further investigation with primary percutaneous intervention should be considered especially if the patient has risk factors including diabetes, renal failure and heart failure.

\section{Drug therapy}

In addition to reperfusion, drug therapy improves the outcomes of acute coronary syndrome.

\section{Antiplatelet drugs}

Antiplatelet therapy is a cornerstone of acute coronary syndrome management.

\section{Aspirin}

Oral aspirin significantly reduces the risk of recurrent myocardial infarction, strokes and death at 12 months post-myocardial infarction. ${ }^{13}$ In the absence of contraindications, a loading dose of $300 \mathrm{mg}$ should be given as soon as possible after the patient presents. Maximum platelet inhibition occurs within two hours.

\section{$P 2 Y_{12}$ inhibitors}

P2Y ${ }_{12}$ inhibitors available in Australia are clopidogrel and ticagrelor. The choice of drug varies between regions, however clinical guidelines recommend ticagrelor over clopidogrel in the absence of other considerations such as a need for long-term oral anticoagulation, an elevated bleeding risk or concerns about patient adherence with ticagrelor's twice-daily dosing regimen. This recommendation is due to a greater reduction in the 12-month composite end point of death from cardiovascular causes, stroke and myocardial infarction with ticagrelor compared to clopidogrel. ${ }^{14}$ Patients should be given loading doses of ticagrelor (180 mg) or clopidogrel $(600 \mathrm{mg}$ or $300 \mathrm{mg}$ ) at the time of diagnosis. Peak platelet inhibition occurs within two hours with ticagrelor, two hours with clopidogrel $600 \mathrm{mg}$ and eight hours with clopidogrel $300 \mathrm{mg}^{15}$

Pre-treatment with P2Y $Y_{12}$ inhibitors before coronary angiography is not necessary, in the absence of very high-risk features including ongoing chest pain or anticipated delays in angiography or the transfer to a primary percutaneous intervention centre, as pre-treatment does not reduce ischaemic events. Furthermore, the likelihood of requiring coronary artery bypass grafting surgery should be considered before administering P2 $\mathrm{Y}_{12}$ inhibitors. Patients with haemodynamic instability or extensive ischaemic ECG changes are more likely to require surgery, and P2 $\mathrm{Y}_{12}$ inhibitor therapy can delay surgery and increase perioperative bleeding.

\section{Anticoagulation}

The goal of anticoagulation in acute coronary syndrome is to prevent clot propagation or reformation, in combination with antiplatelet therapy. Enoxaparin or unfractionated heparin may be used. In the case of fibrinolysis for patients with a STEMI, an intravenous bolus of enoxaparin $0.3 \mathrm{mg} / \mathrm{kg}$ is recommended for patients under 75 years old (not recommended above 75 years). This is followed by subcutaneous enoxaparin $1 \mathrm{mg} / \mathrm{kg}$ (up to a maximum dose $100 \mathrm{mg}$ in people with normal renal function) and $0.75 \mathrm{mg} / \mathrm{kg}$ above the age of 75 years.

Anticoagulation should continue until a primary percutaneous intervention is performed. If a conservative, non-invasive strategy is adopted, anticoagulation should be given for at least 48 hours, or for the duration of hospitalisation up to eight days. ${ }^{16-18}$ The patient's renal function should be checked before determining the ongoing anticoagulant dose.

\section{Secondary prevention}

Following acute management of myocardial infarction, secondary prevention strategies should start before the patient leaves hospital (see Table). ${ }^{19}$ These strategies are vital in minimising the risk of further atherosclerotic cardiovascular events. Additionally, referral for cardiac rehabilitation is recommended for patients recovering from acute coronary syndrome. 


\section{Table Drugs used in secondary prevention of acute coronary syndrome}

\begin{tabular}{ll} 
Drug & Recommendations \\
\hline Aspirin & Continue indefinitely unless contraindicated. \\
\hline P2Y $Y_{12}$ inhibitors & $\begin{array}{l}\text { Continue for at least } 12 \text { months post-acute coronary syndrome, irrespective of whether coronary } \\
\text { revascularisation has occurred, due to reduction in risk of recurrent acute coronary syndrome, } \\
\text { stroke or death. } \\
\text { Continuation beyond } 12 \text { months should be decided in conjunction with the treating cardiologist. }\end{array}$ \\
& $\begin{array}{l}\text { The highest tolerated dose of statins should be continued indefinitely to achieve low-density } \\
\text { Statins }\end{array}$ \\
& Consider addition of ezetimibe. \\
& Consider PCSK9 inhibitor therapy if low-density lipoprotein remains $>2.6$ mmol/L despite \\
& maximally tolerated doses of statin and ezetimibe.
\end{tabular}

Renin-angiotensin Post-acute coronary syndrome, ACE inhibitor or angiotensin receptor antagonist limit infarct antagonists size and left ventricular remodelling, and reduce overall cardiovascular mortality, non-fatal myocardial infarction and stroke. ${ }^{3}$

These drugs should be increased to the highest tolerated doses for maximum benefit, especially if there is concurrent hypertension or left ventricular dysfunction. ${ }^{19}$ Blood pressure targets of $130-140 \mathrm{mmHg}$ systolic and $80-90 \mathrm{mmHg}$ diastolic should be considered.

Beta blockers The benefit of beta blockers is equivocal in patients with preserved left ventricular function, especially beyond one year after infarction, in the modern era of primary percutaneous coronary intervention. They can be used, however, if further antihypertensive drugs are required.

\section{Conclusion}

The guidelines for the management of acute coronary syndromes have evolved beyond providing a static framework to ensure timely coronary intervention to decrease morbidity and mortality. They now compel greater clinical judgement in redefining myocardial injury and myocardial infarction. This includes consideration of the patient's bleeding and ischaemic risk profile before intervention. The aim is to ensure delivery of appropriate care for the patients most likely to derive therapeutic benefits. $\varangle$

\section{Conflicts of interest: Derek Chew's institution has} received research funds from AstraZeneca.

\section{REFERENCES}

1. Thygesen K, Alpert JS, Jaffe AS, Chaitman BR, Bax JJ, Morrow DA, et al.; Executive Group on behalf of the Joint European Society of Cardiology (ESC)/American College of Cardiology (ACC)/American Heart Association (AHA)/ World Heart Federation (WHF) Task Force for the Universal Definition of Myocardial Infarction. Fourth universal definition of myocardial infarction. Circulation 2018;138:e618-51. https://doi.org/10.1161/CIR.0000000000000617

2. Australian Resuscitation Council. 2021. The ARC guidelines. https://resus.org.au/guidelines [cited 2021 Sep 17]

3. Chew DP, Scott IA, Cullen L, French JK, Briffa TG Tideman PA, et al.; NHFA/CSANZ ACS Guideline 2016 Executive Working Group. National Heart Foundation of Australia \& Cardiac Society of Australia and New Zealand: Australian clinical guidelines for the management of acute coronary syndromes 2016. Heart Lung Circ 2016;25:895-951. https://doi.org/10.1016/j.hlc.2016.06.789

4. Keeley EC, Boura JA, Grines CL. Primary angioplasty versus intravenous thrombolytic therapy for acute myocardial infarction: a quantitative review of 23 randomised trials. Lancet 2003;361:13-20. https://doi.org/ 10.1016/S0140-6736(03)12113-7

5. Fibrinolytic Therapy Trialists' (FTT) Collaborative Group. Indications for fibrinolytic therapy in suspected acute myocardial infarction: collaborative overview of early mortality and major morbidity results from all randomised trials of more than 1000 patients. Fibrinolytic Therapy Trialists' (FTT) Collaborative Group. Lancet 1994;343:311-22. https://doi.org/10.1016/S0140-6736(94)91161-4
6. Cantor WJ, Fitchett D, Borgundvaag B, Ducas J, Heffernan M, Cohen EA, et al.; TRANSFER-AMI Trial Investigators. Routine early angioplasty after fibrinolysis for acute myocardial infarction. N Engl J Med 2009;360:2705-18. https://doi.org/10.1056/NEJMoa0808276

7. Wijeysundera $\mathrm{HC}$, Vijayaraghavan R, Nallamothu BK, Foody JM, Krumholz HM, Phillips CO, et al. Rescue angioplasty or repeat fibrinolysis after failed fibrinolytic therapy for ST-segment myocardial infarction: a meta-analysis of randomized trials. J Am Coll Cardiol 2007;49:422-30. https://doi.org/10.1016/j.jacc.2006.09.033

8. Alfredsson J, Clayton T, Damman P, Fox KA, Fredriksson M, Lagerqvist $B$, et al. Impact of an invasive strategy on 5 years outcome in men and women with non-ST-segment elevation acute coronary syndromes. Am Heart J 2014;168:522-9. https://doi.org/10.1016/j.ahj.2014.06.025

9. Damman P, Wallentin L, Fox KA, Windhausen F, Hirsch A, Clayton $\mathrm{T}$, et al. Long-term cardiovascular mortality after procedure-related or spontaneous myocardial infarction in patients with non-ST-segment elevation acute coronary syndrome: a collaborative analysis of individual patient data from the FRISC II, ICTUS, and RITA-3 trials (FIR). Circulation 2012;125:568-76. https://doi.org/10.1161/ CIRCULATIONAHA.111.061663

10. Fox KA, Clayton TC, Damman P, Pocock SJ, de Winter RJ, Tijssen JG, et al.; FIR Collaboration. Long-term outcome of a routine versus selective invasive strategy in patients with non-ST-segment elevation acute coronary syndrome a meta-analysis of individual patient data. J Am Coll Cardiol 2010;55:2435-45. https://doi.org/10.1016/j.jacc.2010.03.007 
11. Hoenig MR, Aroney CN, Scott IA. Early invasive versus conservative strategies for unstable angina and nonST elevation myocardial infarction in the stent era. Cochrane Database Syst Rev 2010:CD004815 https://doi.org/10.1002/14651858.CD004815.pub3

12. Chew DP, Scott IA, Cullen L, French JK, Briffa TG, Tideman PA, et al. National Heart Foundation of Australia and Cardiac Society of Australia and New Zealand: Australian clinical guidelines for the management of acute coronary syndromes 2016. Heart Lung Circ 2016;25:895-951. https://doi.org/10.1016/j.hlc.2016.06.789

13. Antithrombotic Trialists' Collaboration. Collaborative metaanalysis of randomised trials of antiplatelet therapy for prevention of death, myocardial infarction, and stroke in high risk patients. BMJ 2002;324:71-86. https://doi.org/10.1136/ bmj.324.7329.7

14. Wallentin L, Becker RC, Budaj A, Cannon CP, Emanuelsson H, Held C, et al.; PLATO Investigators. Ticagrelor versus clopidogrel in patients with acute coronary syndromes. N Engl J Med 2009:361:1045-57. https://doi.org/10.1056/ NEJMoa0904327

15. Indraratna P, Cao C. New antiplatelet drugs for acute coronary syndrome. Aust Prescr 2014:37:182-6. https://doi.org/10.18773/austprescr.2014.074
16. Antman EM, Morrow DA, McCabe CH, Murphy SA, Ruda M, Sadowski Z, et al.; ExTRACT-TIMI 25 Investigators. Enoxaparin versus unfractionated heparin with fibrinolysis for ST-elevation myocardial infarction. N Engl J Med 2006;354:1477-88. https://doi.org/10.1056/NEJMoa060898

17. Assessment of the Safety and Efficacy of a New Thrombolytic Regimen (ASSENT)-3 Investigators. Efficacy and safety of tenecteplase in combination with enoxaparin, abciximab, or unfractionated heparin: the ASSENT-3 randomised trial in acute myocardial infarction. Lancet 2001;358:605-13. https://doi.org/10.1016/S0140-6736(01)05775-0

18. Wallentin L, Goldstein P, Armstrong PW, Granger CB, Adgey AA, Arntz HR, et al. Efficacy and safety of tenecteplase in combination with the low-molecular-weight heparin enoxaparin or unfractionated heparin in the prehospital setting: the Assessment of the Safety and Efficacy of a New Thrombolytic Regimen (ASSENT)-3 PLUS randomized trial in acute myocardial infarction. Circulation 2003;108:135-42. https://doi.org/10.1161/01.CIR.0000081659.72985.A8

19. Yusuf S, Sleight P, Pogue J, Bosch J, Davies R, Dagenais G; Heart Outcomes Prevention Evaluation Study Investigators. Effects of an angiotensin-converting-enzyme inhibitor, ramipril, on cardiovascular events in high-risk patients. N Engl J Med 2000;342:145-53. https://doi.org/10.1056/ NEJM200001203420301 